\title{
$\begin{array}{llllll}\mathbf{S} & \mathbf{P} & \mathbf{A} & \mathbf{C} & \mathbf{E} & \mathbf{S}\end{array}$
}

\section{TUNNELS OF VOICES. MINING SOUNDSCAPES AND MEMORIES IN SOUTH WEST SARDINIA}

\author{
FELICE TIRAGALLO \\ DEPARTMENT OF HUMANITIES, LANGUAGES AND CULTURAL HERITAGE \\ UNIVERSITY OF CAGLIARI
}

For the anthropologist, the work of mining seems to be characterised by a specific set of spatial, material, corporeal and sensorial relations. On-going debates in anthropology emphasize the prominence of a direct approach to this range of features of experience, in correlation with a need to understand how they are connected with social meanings. This article uses such an approach to investigate how the sensory experiences of mining are shared by miners as a community of practice. At the same time, the historical decline of mining activity is inexorably restricting mining landscapes and cultures to the heritage of the past.

In European mining districts, such as South West Sardinia (Italy), a rich heritage of the memory of an abandoned mining world coexists with a number of advanced, government subsidised mining plants that are just ceasing to be active. In this context, a particular form-of-life seems to appear that links miners, witnesses of a recent mining past, with local communities that are still entangled in mining activity. The existence of a rich aural sensitivity underground, recorded by the research project's filmmaking, is closely related to the way in which former miners "give voice to" and "feel" what they are saying.

Sensory landscapes of mining life are linked to the subjective voices which express their history and memory. Starting from an ethnographic research, I shall discuss the relationship between performative aspects of oral memory, and the aural and visual dimensions of modern-day mining work.

KE Y W O R D S : mining soundscapes, miner voices, sensorial agency, memory.

In this article*, I discuss and evaluate some aspects of the sound environment of the Sardinian mining world, which enable us to grasp peculiar and indicative elements of mining culture in an anthropological sense. The research is based on fieldwork carried out by the author with Paola Atzeni between the autumn of 2006 and the summer of 2007 in the Sardinian sub-region of Sulcis-Iglesiente. The research consisted of creating extensive digital video documentation of mining activity and conducting

* I am very grateful for the attention, with which the editors and reviewers read and commented on the text and for the suggestions they gave me. 
twenty biographical interviews, both with former miners and with miners who were still working. We were able to obtain around thirty hours of recordings, designed and created with the aim of setting up an audiovisual archive of the Serbariu Great Mine, an important museum that at the time was still under construction. This ethnographic material was therefore created to answer more general questions about the material culture and living memory of the miners and to become an archival source, and only later was it questioned for the purposes set out in this article. In any case, it is material that is evidence of the writer's direct involvement as producer and filmmaker of that film footage, and is therefore the main, if not the only, trace of his fieldwork.

In the first section of this text, I will give a brief picture of the historical penetration of mining production into Sardinia, and try to highlight its role in the historical experience of modernity on the island. In the second part, I will indicate the theoretical framework to which I intend to refer in constructing a specific discourse on the anthropology of local sounds. In the third section, in an interpretative perspective, I will try to justify my intention to connect the mineral sound landscape perceived in the subsoil with the vocal and performative dimension of the miners' words. In the fourth section I analyze, using some parts of the recordings, my experience of immersion in the soundscape of the subsoil and discuss some applicable theoretical approaches. I will also analyze some passages from the interviews with the miners with the aim of illustrating their connection with the soundscape.

\section{THE SOUNDS AND VOICES OF A DISPUTED ACTIVITY}

Nowadays, mineral processing can seem an extremely under-developed industry, constituting a stark contrast to a de-materialized and digitized economy. Secluded in ecologically de-regulated areas, mining activity involves millions of people in contexts where conflict between multinational groups and local stakeholders occurs, and indeed is ineluctable, leading to environmental crises and social emergencies. This activity is concentrated in places like China, South America, Oceania and other areas (Godoy 1985, Pandey 2015, D'Angelo and Pijpers 2018, Ballard and Banks 2003).

Despite being highly specialized, even compared to the world situation, mining industries retain considerable importance in Europe, even if nowadays they play a minor role in the energy production sector when compared to other sources, such as gas, oil, nuclear and renewable sources. ${ }^{\mathrm{I}}$ The history of coal production in particular

I In 2017, the energy mix in the EU, meaning the range of energy sources available, was mainly composed of: petroleum products (including crude oil) (36\%), natural gas (23\%), solid fossil fuels (including coal) (I5 \%), renewable energy (I4 \%) and nuclear energy (I2 \%). https://ec.europa.eu/eurostat/cache/infographs/energy/bloc-2a.html (accessed I6.oI.2020). 
countries, such as Italy for example, has been determined by the political circumstances of the $20^{\text {th }}$ century. The strategic needs of redevelopment after World War II caused coal regions to flourish, whereas thereafter their relevance has progressively decreased as a result of their lessening economic efficiency and the increasing value of other energy sources (Rakowski 20I6, Sapelli 2008, Ruju 2008). Nevertheless, in a period covering the $19^{\text {th }}$ and $20^{\text {th }}$ centuries that lasted for around 150 years, these areas in many cases constituted the earliest experience of the industrial mode of production experienced by human groups and territories which, up to that point, had been marked by a traditional agro-pastoral life. ${ }^{2}$

The mining region of South-West Sardinia, made up of the Iglesiente Region specializing in metals (lead and zinc) and the Sulcis coal-mining area, is still today an example of this type of radical juxtaposition. Unlike the Italian Alpine regions where mining activity has often been of a temporary, intermittent and seasonal nature, sometimes compatible with a regime of rural activities strongly concentrated in the springearly autumn period (see Sanga and Viazzo 20I6), mines on the island have always embodied a radical alternative to traditional rural models (Manconi 1986, Accardo 1998). In this situation, being miners meant, in most though not all cases, acquiring, incorporating and strengthening an entirely new personal and collective identity. In Sardinia, the farmers who became miners abandoned a way of working based on the use of human and animal force, and a mode of social relationships based on individualism and limited forms of cooperation, to become part of a complex production organism based on artificial energy and on hierarchical and class relations (Atzeni 2007).

\section{SOUND IN THE MINE AS A CULTURAL FIELD}

This paper aims to study, through local ethnography, some sensorial aspects of this cultural condition. For the anthropologist, mining work seems to be characterised by a specific set of spatial, material, corporeal and sensorial relations. An ongoing debate in anthropology (e.g. Pink 2009, Ingold 200Ia, 2011a, 20Irb, Miller 2005) emphasizes a need to give prominence to a direct approach to these aspects of experience, along with a need to understand how they are connected with the social meanings. I use this approach as a basis to investigate how miners share the sensory experiences of mining as a community of practice (Atzeni 20I2a, 20I2b). In South-West Sardinia, an

2 This was a backward mode of production when compared to other continental models of the early I90os focused on: dry cereal-growing, use of human and animal energy, customary forms of fund management, a sharp social distinction between producers and the owners of the funds, and finally the existence of a complex hierarchy of owners, sharecroppers, tenants and day labourers (see Angioni 1974). 
unusual situation has come about in which a rich heritage of the memory of an abandoned mining world coexists with some advanced, government-subsidised mining plants that are still active. In this context, a particular form-of-life seems to emerge that links the miners, witnesses of a recent mining past, with local communities that are still involved in mining activity. The presence in the subsoil of a dense auditory sensoriality, documented during the realization of the research project and analyzed in line with a series of fundamental contributions in the anthropology of sound (Schafer 1994, Feld 1991a, 199Ib, etc.), is in particular linked to an ethnopragmatic dimension (Duranti 2007) of the mining narrative: that is to say, to the way in which ex-miners "take the floor" to give voice to their experiences and "feel" what they are saying. In other words, it is the connection between the auditory world of the miners and their words that this paper will try to explore.

Among the range of possible approaches to the study of sounds, I intend to focus on auditory anthropology, a recently born field that combines an "archival" interest in sounds as cultural products with an expansion and articulation of the purposes of the documentation of music, orality and storytelling, including the active participation of interlocutors in shared performance (Samuels et al. 2010, 335).

The recordings of a certain sound environment or social situation made by the ethnographer can be interpretative, creative, empirical, hermeneutical or analytical, and can be rendered in an acoustic form. Even in a very different study tradition, such as that of oral history, Alessandro Portelli has written enlightening pages on the shared and collaborative nature of the interviewee-interviewer performance, and on the often-neglected problem of oral form. Pauses, rhythms and the speed of emission of the voice within the same narration are determining factors for its understanding, and thus a constitutive part of the cultural phenomenon (Portelli 20I7, 9).

Schafer defined the soundscape as "a circulating public entity that is a produced effect of social practices, politics and ideologies, while also being implicated in the shaping of those practices, politics and ideologies" (in Samuels et al. 2010, 330). The concept of soundscape proposed by Schafer arises therefore from the need to establish "a total appreciation of the acoustic environment" (Schafer 1994, 205). In some ways - he notes - the soundscape is the analogue of the landscape, because it includes everything to which the ear is exposed in a specific phonic setting. Like a landscape, it contains the contradictory forces of the natural and the cultural, the fleeting and the repetitive, the improvised and the deliberately produced. Moreover, just as the landscape is made up of cultural histories, of ideologies and practices of vision, so too does the soundscape involve listening as a cultural practice (Samuels et al. 2010, 330). Schafer proposes three categories for the analysis and classification of soundscapes: a) keynote sounds; b) signals; and c) soundmarks together with archetypal sounds. The first group of sounds are the contextual sounds in a given environment: wind, water, forests, plains, birds, insects, animals, etc. The second kind are the 
"consciously listened to" sounds in the foreground (Schafer 1994, 9-10), while the third is a communitarian sound, which acquires value and importance uniquely in a given community. I will try to use this classification grid to describe the results of my fieldwork.

While these are the points of reference chosen to investigate the sound environment of the mine, I have also tried to identify a similar key of interpretation in relation to the second auditory dimension studied: that of the miners' voices. Alessandro Duranti's ethnopragmatic perspective helps us to gain a deeper understanding of the orality of our miners, moving from a strictly denotative level to a sense of a connotative richness of the word as performance: a dimension which needs to be incorporated in constructing social facts. Ethnopragmatics deals with speaking as a form of social organization and deepens the study of activities in which language plays a primary role for social construction (Duranti 2007, I4). This approach argues that it is a performative power combined with the power of representation that together express the quality of agency which is represented and realized in language. It was John Austin who, as Duranti notes, first spoke of language in terms of force, "strength, effectiveness", rather than "meaning" (Duranti 2007, 4I).

On the one hand, therefore, the spaces, the times, the technical actions and the interactions between man and nature, between man and machine and - often through these machines with nature, qualify the mines as a soundscape with peculiar characteristics. It is a soundscape in which the propagation of the sound of underground activities is the main, but not the only, means by which humans generate the particular ecological niche of the mining gallery.

A great number of the miners interviewed by Paola Atzeni in the many years of ethnographic work that preceded our collaboration in 2006-2007 clarified how acquiring specific perceptive skills was important for their safety. For example, in the language of the miners, tenni ogu [lit. "having an eye", i.e. watching closely] and tenni origa [lit. "having an ear", i.e. listening carefully] $]^{3}$ meant having technically trained eyes and ears. These expressions signify that their sight and hearing had been culturally enhanced so as to be able to perceive is avvisus [the warnings], the visual and auditory signals of the dangers that marked the mining tradition (Atzeni 2007, I39).

On the other hand, in my opinion, the historical singularity of Sardinias mining history as an industrial experience, and therefore as a direct experience of modernity, has led to a second level of auditory value. These are the voices of the miners, expressing the deep awareness our interlocutors have of the public relevance (in the sense of rarity, preciousness, exemplariness and social utility) of their individual and collective experience.

3 Lit. "Always keep your eyes and ears open". 


\section{SENSORY TRACES OF MINING}

Our ethnographic research began in 2006-2007 with the aim of building a sensory testimony of mining memories and mining work in Sardinia, in order to establish an ethno-anthropological section in the Museum of the Great Serbariu Mine, the most important ethnographic mining museum in the region. The subjects of the ethnographic audiovisual interviews that Paola Atzeni and I conducted included the miners' biographies and the ways in which they maintain social relationships, their perceptions of their workspace, production processes, operational chains, a historical and political dimension and the roles of the unions that had existed during their lifetimes. We further set ourselves a non-textual and non-conceptual goal: that of returning the sensoriality of a modern mine by means of an audiovisual depiction, produced through repeated recording sessions made in the subsoil during ordinary coal mining activity in the Nuraxi-Figus Monte Sinni. In a subsequent analytical part of the process, I decided to investigate the complete corpus of approximately thirty hours of recordings, placing its sensory-auditory dimension in the foreground.

My hypothesis is that a perspective of aural anthropology can be used to interpret not only the auditory aspects of mining life as a productive action, but also the voices of previous generations of former miners as they remember through a performative act. Such an approach allows sensory data ("sounds" and "voices", but not only) to be compared and interpreted "beyond" their quality as "messages". In doing so, I shall firstly make reference to David MacDougall's reflections on the subject of the perceivable through filming and writing, which I believe in some aspects can be extended to auditory perception and recording (MacDougall 1998, 265). Secondly, I refer to recent contributions calling for a cognitive reconsideration of the senses in ethnographic experience (Pink 2009). Thirdly, I intend to highlight some of Tim Ingold's reflections on the dynamics of "expert environments", pertinent in my opinion to the understanding of the sensorial world of mining gallery work, as a site of a multi-subject expert practice (Ingold 20Irb).

\section{AUDIOVISUAL METHODS AND SENSORY EXPERIENCE}

Following the Lamps is a film project with two narrative threads, which stemmed from the above-mentioned research program. The first thread concerns the memories of older generations who have lived and worked in the Serbariu carboniferous districts; the second documents modern-day life (2006-2007) in the Nuraxi Figus - Monte Sinni Mine ${ }^{4}$. In my analysis, I intend to extract visual and sound elements from the

4 F. Tiragallo, Following the Lamps. Visual Traces of Mining Life, ethnographic research: Paola Atzeni, Felice Tiragallo; images: Felice Tiragallo, Andrea Mura; editing: Andrea Mura, Annalisa Porru; 
part of the film that documents the sensorial landscape on the basis of the typology elaborated by Schafer (keynote sounds; signals; community sounds)s.

The methods of video film documentation of mining activities, that we used, were inspired by the approach of "observational cinema" as described by Young (1975), Grimshaw and Ravetz (2016) and MacDougall (1998). In MacDougall's spirit of the use of an "unprivileged camera style", we adopted, with respect to the actions that

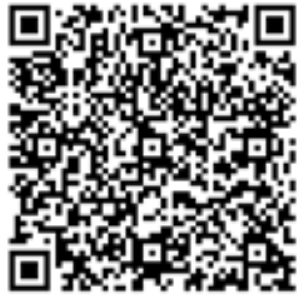

Following the Lamps took place in the subsoil, a rigorous policy of unobtrusive observation of the activity in the mining plant, a total abstention from staging, retakes or visual and sound alterations of the environment, and a broad preference for long takes. This was important since it permitted us to adapt the sound flow to the flow of visual observation, thus obtaining long sequences that allowed easy access to both the complexity of the documented technical actions and to the detail, and to the depth and three-dimensionality of the sound environment in which they took place. The next operation was to re-view and re-listen to the parts of the film that concerned the subsoil, by removing the visual plane from perception and focusing attention on the auditory dimension. The audio materials were obtained through the use of a cardioid microphone coupled to the video camera, which reproduced the soundscape in a partially selective way with respect to the researcher's hearing.

Now, in seeking to move towards a "total appreciation" of the acoustic mining environment, let us start by identifying Schafer's three categories that allow a progressive "purification" of sound, or in other words that enable an isolation of particular aspects of the continuum of a given sound environment. In this regard, we could say that the "keynote sounds" and "signals" appear in this specific audio context as closely connected, almost intertwined, dimensions. In fact, in the mining gallery the contextual sounds

production: University of Cagliari, Laboratory of Visual Ethnography - Italian Centre of Charcoal Culture; duration: I: 4I'35"; year: 2008; filming locations: Carbonia, Nuraxi Figus Mine - Monte Sinni. The film is structured as follows: I) Going to the mine (arrival at the mine, 3'30"; the decision to go to the mine - memory, $77^{\prime} 40^{\prime \prime}$; descent into the pit $\left.33^{\prime} 30 "\right)$. 2) Advancements (the first days in the mine - memory, 8'о2"; progress inside the tunnel, 3' Іо"; reinforcement of the tunnel roof, $\left.3^{\prime} 29 "\right)$. 3) Movements and knowledge (movements within the gallery, 5 'ı"; technical knowledge and working conditions - memory, II'). 4) Production and safety (coal extraction, 3'30"; perception of danger - memory, 5'40"; the pit scaffolding and the winch, 2'30"). 5) Organization levels (the coal's journey through the wash plant, 5'22"; official hierarchies and de facto hierarchies - memory, 9'15"). 6) Conflicts and parties (political and trade union struggles - memory, I5'32"; the Feast of Santa Barbara in the mine, December 4, 2006, 4'04").

5 Selection from Following the Lamps. Visual Traces of Mining Life https://rcin.org.pl/Content/I22005/Audio/WA308 I52I96 P366 Tunnels-of-Voices.mp4. 
that determine a seemingly bottomless flow of meaning are the rumblings of the various service systems, especially ventilation devices and flowing water. These elements indicate the total artificiality, but also the total humanization of the landscape. The sound "signals", in this case, are simply those of the contextual sounds that are intentionally listened to: they are thus comprised of a mix of human and non-human sounds.

The "electrical revolution" might be expected to produce a sound that is less and less tuned to a human scale. In this soundscape, however, it forms the basis of a complex network of meaningful sounds that weave together noises and perceptions of machinery with contact between machine and matter, which in turn is fused with a complex network of human voices, warnings, indications, rapid dialogues and references to the gigantic "continuous miner" and other devices in action. Human control is here tightly intertwined with the action of machines. Man is bodily present, and his body and the sound of his voice dialogues with the machinery, with the gallery and with the space. It is this mixture that determines the third category, that of archetypal sounds, which we can identify in the variations, pauses, rhythms and briefness of oral communication in the gallery.

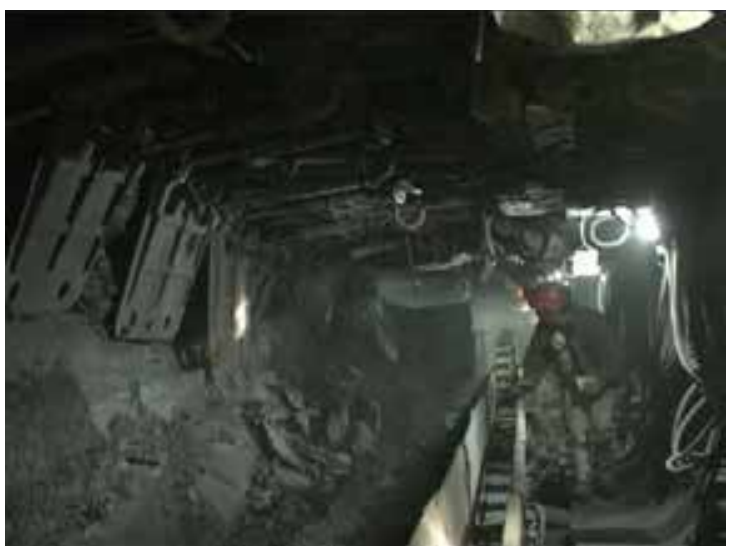

Coal cultivation, in the Monte Sinni Nuraxi Figus coal mine, 2007

\section{SOUNDS}

The arrival of the workers. In October 2006, before dawn, a bus arrives at the entrance to the Monte Sinni - Nuraxi Figus Mine. In the silence broken only by the noise of the diesel engine, the 7.00 am shift workers come down. Many voices are heard indoors, the miners are in their locker room, open taps, waiting voices. Sparse and muted noises as the lamps are taken from the lamp room, upon receiving their identification tags. 
"Giancarlo, hurry up!". Straps laced, greetings, whistles, laughter. Descent into the pit: noises of footsteps on metal, of sliding gates set in motion and of mechanisms that lock and engage. An acoustic signal, almost a vibration, indicates the beginning of the descent of the cage; voices emerge, passages of conversation between miners. Arguments that are futile, or mildly playful. Sliding of structures inside metal runners, with cyclical sound peaks. Arrival. Opening the gates, voices that move away into space and propagate in wider and more echo-rich environments than the circumscribed and rounded sounds of the elevator cage. Heading forward. Descent noise. Removing of the reinforcement, falling of stones and crushed rock. Rotating machine, its moving teeth produce a digging noise, noises of electric voltages, combined with noises of materials crushed and transported on a conveyor belt. Cyclical noises. "Thirty-six, eight": Transmission of data, readings from sensors placed in the reinforcement. "Go past the hole ... no ... wait ... come on, Salvatore ... anyway, I'll tell you that we were better before ..." Electric motors on. "Preparation, here ...". Noise of a live electrical apparatus, a continuous, prolonged note. Assembly of the reinforcement dowel. Metal that hits and scrapes against other metal. Pneumatic hammers in action, in the background. Lots of miners talking. Mining noises. Noise of air pressure equipment, operating, gears, engine transmission chains and coal mining. Noise of metal against the coal seam. Ascent. The Toyota $4 \times 4$ that goes up along the shaft and finally reaches the open air, the roaring noise of the engine and of its progress forward grows louder and becomes more free and more linear.

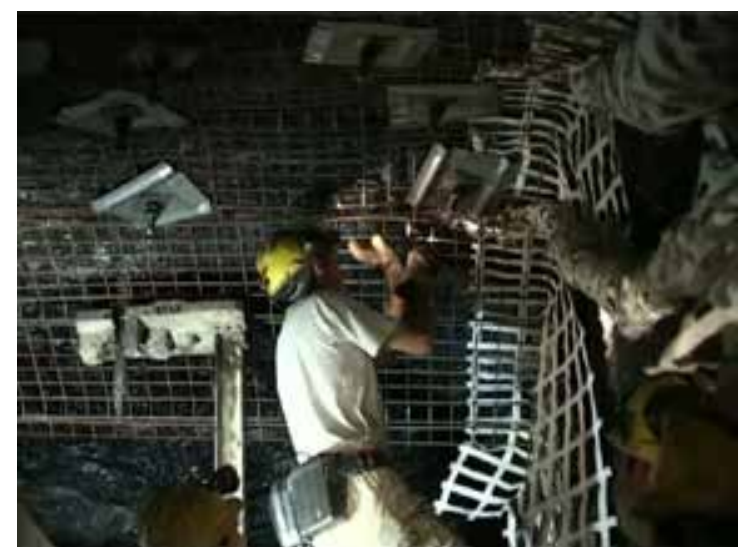

Tunnel reinforcement, in the Monte Sinni Nuraxi Figus coal mine, 2007

What does the soundscape of the mine presented here convey? At first glance, we see men, processes, devices and artefacts at work in an underground environment. But if we take the Monte Sinni production environment as a whole, the materiality 
of the cultural product it contains seems to express itself best of all in the sound dimension; in a complex and multi-layered interweaving of noises produced by the movement of the miners' bodies; in voices that exchange information and reveal positions in space to each other; in tones of voice the modulations of which either speed up or slow down actions, both in the bodies that emitted these signals and in the bodies that receive them; rhythmic sounds emitted by machinery and devices powered by electricity (hence the monotonous and linear tonality of these sound waves), which in turn are modulated in an extremely precise way by operators, through manual pressure on commands like joy-sticks, buttons, levers and switches.

This dense and multidimensional sound indicates the presence of a complex artefact in which people do not work from above that world, but rather from within it. In this sense, every technical activity is comparable to a weaving or intertwining: acting in the world is a process of continuously intertwining our lives with others, and with the other elements of the environment. It is within this intertwining that our production projects come into being, not in a disembodied "world of ideas" (see Ingold 200Ia, I89-196).

The skills in this environment are not individual: they are not those of each particular actor. "They are properties of the entire system of relationships constituted by the presence of the agent (human and non-human) in a richly structured environment" (Ingold 20ora, I50). Ingold's study calls for an ecological approach to an active intertwining of relationships, because an operator "looks and listens while at work" (ibid.).

Mining activity would thus consist of a set of "tasks". Each of these tasks takes its meaning from the position it occupies within the set of other tasks, performed one after the other, or in parallel, and usually in synergy, by many people. In the Ingoldian taskscape,

the apprentice looks, hears and listens to the movement of the expert and tries - through repeated attempts to bring his bodily movements in line with those of his attention, so as to obtain a rhythmic adjustment of the perception of the action that is the basis of the skillful performance. (Ingold 20orb, 194)

In Ingold's hypothesis, several critical points emerge with regard to the commonly understood notion of soundscape. In the first place, the author argues that the idea of being able to conceive the soundscape in analogy with the visual landscape, as a spatially delimited environment in which levels of auditory experiences coexist in a constant relationship with each other, is groundless. Instead, the sensorial registers function as an inextricable clump, and we should not count too much on the utility of separating, isolating or purifying visual registers from sound registers. If we attempt in both cases (and in other sensory directions) to try to "reproduce" each stimulus in an environment deprived of all the others, we risk breaking down something that would be better interpreted as a unitary phenomenon. 
The second mistake is to allow the metaphorical influence of the landscape as a visual experience to force us to implicitly construct an analogy that connects sound to vision. Sound is a phenomenon of experience, of our bodily immersion in the world. Thus sound is not what we hear, but the medium of our auditory perception; just as light is not what we see, but the means that allows us to experience what is apparent. This is the crux of the argument. We need to distance ourselves from the notion of sound emplacement:

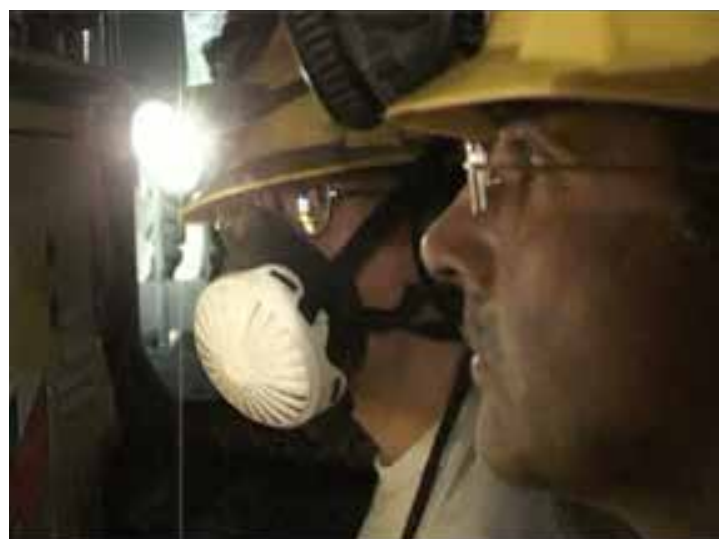

Miners lead the continuous miner in the Monte Sinni Nuraxi Figus coal mine, 2007

... Finally, if sound is like the wind, then it will not stay put, not does it put persons or things in their place. Sound flows, as wind blows, along irregular, winding paths, and the places it describes are like eddies, formed by a circular movement around rather than a fixed location within. To follow sound, that is to listen, is to wander the same paths. Attentive listening, as opposed to passive hearing, surely entails the very opposite of emplacement. We may, in practice, be anchored to the ground, but it is not sound that provides the anchor. Again the analogy with flying a kite is apposite. (Ingold 2007, I3)

In terms of Ingold's hypothesis, the miners are not mere receptors of sound waves in the subsoil that they select, interpret and react to. Underground sound agency requires that we "resist" sound streams, that they are reacted to by the miners in an oppositional capacity, like the kite that "opposes" the force of the wind and its changing direction. The sound experience of the subsoil produces a habitus (in the Bourdieian sense) of an extension of subjectivity: you perceive your corporeality in terms intertwined with that of others, and with the subterranean strata and the machinery. In the subsoil, the individual conscience seems to be compressed and re-emerges only above ground. Thus, separation from the workplace seems to be the necessary condition for "taking back the word", which is an equivalent for fully "taking back identity". 


\section{VOICES}

The subject of my interest in this section is not only the discursive content of the individual spoken contributions, but also the complex of phonic, rhythmic and tonal qualities of the documented voices. I allude to what MacDougall has defined as the value of the subjective voice in ethnographic documentaries, but also recall his warning that his use of the word "voice" has an ambivalent sense:

Voices are even more completely embodied than faces, for the voice belongs to the body. Visual images of people, by contrast, result only from a reflection of light from their bodies. In a corporeal sense, then, these images are passive and secondary, whereas a voice emanates actively from within the body itself: it is a product of the body. (MacDougall I998, 263)

In the pieces of film presented here, the voices of the miners seem to be linked by an internal rhythm, a common mode of sound emission and a calmness full of lucidity and critical control over what they say. They appear to be physically linked to the material qualities of the environment that generated their memories. Here, we are dealing with the presence of the "mine in the body", to quote Paola Atzeni who, during her long ethnographic work with the miners, realized that, in each of the voices she listened to, she could make a detailed evaluation of the degree of physical degeneration of their lungs, due to silicosis and other serious diseases of the airways caused by their job (Atzeni 2015, 75). It seems that the slow pace of the voices of the miners is to some extent a result of the particular conditions in which air is breathed underground, and thus that the preciousness of the words that come out of their mouths is increased by this rarefying of the breath available.

Furthermore, a sense of intimacy between the ethnographer and the miner helps to evoke, in the tone, in the rhythm and in the meditated articulation of words, a separateness of the auditory space in which the meeting takes place. The miners' silences are an integral part of their bodily presence and of their emotional involvement (Bachis 20I7). Here, speaking as a form of social organization and language as a social constraint play primary roles (Duranti 2007, I4). Speaking then as "being-with" has a collaborative nature and entails affective involvement; speaking as "being-for" is also, always, a presentation of one's Self, which lends itself to aesthetic and moral judgment (Duranti 2007, I6).

As I mentioned previously, in dealing with this part of the discussion dedicated to the voices of the miners, I started from the following assumption: in the particular historical situation of south-western Sardinia, the mining industry came into being in the mid-nineteenth century and developed onwards in a rural and pastoral environment, and thus constituted a new and traumatically inserted mode of production. This brought with it an ability to produce material and technical cultures of an algorithmic type (on the notion of embodied and algorithmic knowledge in pre-industrial 
societies see Angioni 1986). In addition to the phonic setting of life in the subsoil, the life of the miners in the topsoil is determined by the forms of a continuous "taking the floor", of speaking publicly, in interventions in union, party and administrative headquarters about issues related to work, struggles, living conditions, and administrative and political life. For this reason, I consider the voices of the miners to be a soundscape complementary to and inseparable from the soundscape of the organic life of the mine.

In order to work on this particular soundscape, it was decided to fully enhance the voices of our interlocutors: in other words, to make clearly audible what MacDougall refers to as the product of the body par excellence. I hereby evaluate some of the choices that were made in carrying out the interviews in order to achieve this effect:

A) The construction of a phonic setting based on domestic environments, free of interference from keynote sounds and other elements extraneous to the voice and the body of the miners. In this setting, the voice functioned both as a "signal" and as a "sound footprint", to use Schafer's terminology, encouraging it to be interpreted as a recurring, peculiar and recognizable element of the social life of the miners under ground.

B) The production of visual documentation that could complete the auditory sensoriality, by placing the body, or at least the parts directly connected to oral communication, at the centre of the recording.

C) I made use of a small radio microphone to bring the device as close as possible to the miners' voices, while the recording of the surrounding sound environment was entrusted to a second panoramic microphone: this captured a background signal, in which the voices of the ethnographers sometimes emerged. I used solar or mixed lighting settings, without producing a sense of detachment through framing and without including the ethnographers in the frame. I believe that in this way a presence of the spectator was inscribed in the sound setting of the interview, making it possible to listen to the words of the miners, with their tones of voice, their pauses and their eloquent silences at the most critical moments, such as in the description of fatal accidents.

\section{A) The Choice to Go to the Mine}

\section{Pietro Cocco:}

... My grandfather was a worker, we were a family of workers, so ... I also became a worker. When I first entered the mine I, at fifteen, already had some mining experience, because I lived in the mine ... Iglesias, with its search for ore around, was a mining site. As a boy, I saw the fruit of the miners' work, the jute bags full of galena ore that came from San Benedetto, carts, horse-drawn carts full of galena sacks that went to the Monteponi foundry. 


\section{Delfino Zara:}

... On the last day of the year, I moved to Cagliari and I was discharged from the military. And then I came directly to Carbonia. Because everyone knew that they had reopened the mines and that they were hiring ... I already had a daughter ... and I needed to work.

\section{Vincenzo Cutaia:}

... We left at the end of October (from Tripolitania) and returned to Italy. Some time before, my brother phoned me to say that he was in Sardinia, in Montevecchio, and he was working in the mine. He told me: "Look maybe you want to come and work here and not go back to Riesi (in Sicily), because here you do your eight hours and then nobody asks you for anything more"... we were farmers and we were always busy ... and then I said to myself: "I have half a mind to go there".

\section{Giorgio Borghesi}

From the age of ten I always thought of going to work in the mine ... the mines of Campiglia (Tuscany) were closed then... but there were still all the abandoned structures, there was the chimney of the copper foundry ... so for us it was a hoot, there were all the piles of minerals, there was chalcopyrite, pyrite, hematite, my idea was to take a mining engineering degree and then go to work in the mine.

\section{B) Technical Skills and Knowledge ${ }^{6}$}

\section{Giorgio Borghesi:}

[He holds his head in his hands, he is about to explain a complicated matter] They were mostly sloping roads, flanked by the removal and the destruction of the props [He uses his two index fingers to indicate two parallel trajectories from bottom to top], leaving filled parts, three meters void, four meters filled, three meters void [his hands separate the spaces]. You went on with these two sloping roads and two swinging boards. Then the panels were joined by isolating the pillars four meters by four meters. How many? It depends on how long the panel was [he stops, hesitates, chooses his words carefully]. From the base gallery to the head gallery. Each pillar, however, had to be four meters. When you got there, you began to ... [stops] to shore up the stack pillars, sleepers ... [he stops again, gives us an almost resigned look that seems to say: "I know it's complicated, I'm trying to explain it as clearly as possible"] Holm oak sleepers, not railroad ones... two, two, two were put [he uses his hands to show the way the pairs of sleepers are laid transversally one on top of each other at $90^{\circ}$ ] until you get to the roof. They were called "Castelle (stacks)". They were wedged into the roof and [he makes a square with his hands] one, one, one were placed, [he draws a square] in the voids. Then we took away the coal in the centre, with the help of some wooden posts. Because generally, in the slant where the pillars had been taken away, there was no iron reinforcement. (...) At that point, however, there was the dismantler who, once he had taken away the pillar, then with the roof up

6 The mining technologies used in coal-mining regions in the period when our ethnographic research witnesses were working are well described in Ottelli 2005. 
[he looks up as if you could see the sky in the tunnel, waving his hands to indicate instability], staying up thanks to the sleepers and he has to recover as many sleepers as possible; there, I used to say, there were the dismantlers who were generally the doyens. Those who had the most experience of all ... they were the untouchables ... the dismantler was a "doyen", he was an "untouchable".

I often used to take a stand when the chief overseer was being a pain in the neck, but he [the dismantler] on the contrary was someone that had to be left alone and that's all [he waves his arms to indicate absoluteness and peremptoriness] I never took the liberty of telling him, "No, take that one off before the other one". Because HE [emphasis] went down there to risk his life ... apart from the fact that he could have run rings around me, he was much older and I had never experienced anything similar (even though I had been an assistant foreman).

\section{C) The Perception of Danger}

\section{Pietro Cocco:}

There are signs. Unmistakable. See the roof that's shattered ... you're in danger and it's there. You learn to recognize it. The mountain makes itself known. Because among other things, in places where a landslide could happen, sometimes material rains down. Every so often you hear "Crack, Crack, Crack". It is a warning. Those who do not obey come to a sticky end. The mountain always warns you. Because there is always something before ... the collapse. A collapse is never just "tac" and that's it. No! Something precedes it. Something falls on you. A small rock. More rocks. That is, it warns you. And then you mustn't be unprepared. The gallery, intact, the rock intact, is one thing. A shattered gallery, no. That's another. You have to watch out. It says: "I am shattered here. Here I might collapse. Because it's not intact". And you learn. You learn these things immediately. A man, if he fears for his life, learns instantly.

\section{Delfino Zara:}

In mid-June I955 ... [long break] eehhh ... An accident in the mine happens, by chance, at the site where I was working. Together with the foreman. Because they organized the work. There was ... the criterion of demanding over-production rather than safety comes back into play. [Here too the basic message is stated in a subdued and somewhat hesitant way, spoken without the emphasis used by some of the other ex-miners interviewed].

So, we find ourselves one morning in a place without reinforcement with imminent danger [language from his political and trade union education] of a landslide on the roof. And the foreman said to the miner: "You prepare the ground. Take out the coal. That under ... be careful. There was a "priest's hat", a particular block of coal. (...), watch out for the "priest's hat", (...). This worker, a Sicilian, you could see that he wasn't careful, he wasn't looking up. The block gave way and fell on him. [He shakes his head briefly, then falls silent, looking down at the ground]. He died the next day at the hospital.

7 As regards the connections between technical knowledge and social status in the mines, Atzeni talks about a solidarity work ethic and notes that the refinement of body and sense techniques underground is socially built and therefore "the techniques of humanization of space, of the body and of work are continually linked to practices of friendship" (Atzeni 2007, 139). 


\section{VOICES AS SOCIAL ACTIONS}

Pietro Cocco is 90 years old. These passages are taken from a long biographical interview that took place in his home in the countryside around Iglesias, in the context of a final re-enactment of his entire life as an opponent of fascism, as a militant and communist leader, a union leader and, finally, as mayor of Carbonia in the 5os and 8os. $\mathrm{He}$ is an eminent figure in the Sulcis-Iglesiente area, used to taking the floor, and with a very precise and narratively structured vision of his life. The construction of a model "identity" of a miner is presented here, at the highest possible level of awareness and coherence between the aspects of technical culture, birth and modern political culture. The sound context is a domestic one, free from any interference from external fields. The sound context is therefore in some ways also public, because Cocco's testimony does not animate or distinguish an intimate place, but rather constructs a narrative that was born and conceived to become a legacy for posterity.

The almost 90-year-old Delfino Zara was a miner in Carbonia from 1946 to the mid-I96os. Unlike Cocco, he comes from a family of farmers from eastern Sardinia. His arrival at the mine determines a clear jump in material and cultural status. His career as a miner is quite regular, as is his militancy in the Communist Party as a basic activist. The sound space of the interview does not take on the form of a public context as happens with Cocco. Zara's narrative is an account that leaves the interlocutor the task of deciding on the ultimate meanings to be attributed to his words. Zara speaks almost "in camera caritatis", as if he were making a confession, in an auditory space of moderate openness. In this case, this confession was overseen by the presence of his eldest son, visible in many shots of the film, who is also a miner and who somehow "controls" this communication space.

Vincenzo Cutaia comes from Sicily, and just like Zara, he too abandoned his roots as a farmer but, unlike the latter, he is the bearer of a story that sounds almost like an odyssey. A story that is determined not so much by material necessity, but by chance and adventure. It is a story that emphasizes change and emancipation, aspects that are completely unknown to Zara. The sound context is not subdued. His voice is almost epic. It tells of a series of values, such as work skills, class solidarity, the choice to "be with the poor", all signs of a fully accomplished path. In this sense, a finality emerges that we found in Cocco but far less in Zara. Even Cutaia's voice has a public dimension which, as he himself states in a part of the interview, is a voice consciously produced for collective memory, but also for pedagogical purposes. For Cutaia, the cultural values of the miners will survive the productive life of the mines.

Giorgio Borghesi spent his entire mining career as "assistant head of service" and then as plant manager. In the mining hierarchy, he therefore occupied a position closer to the leadership than to the class of miners. His testimony is not characterized by 
traumatic or conflicting elements. The mine was a complex world, in which one needed technical skills and an ability to adapt to the highly specialized environment. The goal was to maximize production, and overcome workplace hazards and accidents. Borghesi's whole narrative tends to "rationalize" the work in the subsoil, constantly avoiding dramatic tones, even in the narration of accidents, always trying to bring the discussion back to the level of the complexity and gigantism of the organization of the mine and the professional ability of those who worked there (Carbonia had I2 thousand employees in the early 1950s). Borghesi is not making a grand statement for posterity. The overall tone of the interview is an active testimony, without the implicit elements we found in Zara: it is closer to that of someone with professional "expertise", in which the speaker masterfully describes a technical environment in relation to the "human resources" engaged in it.

\section{FROM SOUNDSCAPES TO GALLERIES OF VOICES}

The miners produce sounds (noises of footsteps, breathing, voices emitted through their lungs and vocal cords). These sound emissions are contemporary and contextual; they expand along tubular paths, they are enhanced more in a linear distance than in an omnidirectional one, and this involves phenomena of refraction and rumbling. The space of sound vibrations therefore favours a selection of distances along the same axis, and phenomena of going beyond rather than perceptual circularity.

In turn, the continuous miner (with the miners who run it), in the Ingoldian perspective, is a kind of kite, which flies governed by the mobile command-based cable module with all its displays and joystick. The continuous miner has sensors (or is a sensorial link) that produce sounds independently, but above all it produces new sounds, external to its body, in contact with the mountain, with the mineral material that constitutes the interior of the mountain. We are not in the presence of a predominately scopic regime. Instead, this is a dynamic, multi-sensory mapping. "Tenni ogu, tenni origa" is not an ancient precept for the separation of sensory regimes, but rather an invitation to a perceptual integration with the environment of the underground and an invitation to move on, bearing in mind the multiple constraints on this form of life.

In Ingoldian terms, the miners oppose the sound: they resist its flow. They connect it to other inputs and move within the inextricable results of this movement. The words they speak in the interviews can then be interpreted as serving the purpose of returning order and hierarchy to this multi-sensorial regime. To affirm one's ability to dominate, at least a posteriori, an environment in which they appear as craftsmen, but in which innumerable encounters and contrasts with other entities force them into a crowded agency. 


\section{BIBLIOGRAPHY}

A c c a r d o A. 1998. Politica, economia e cultura nella Sardegna autonomistica (1948-1998). In A. Accardo, P. Maurandi and L. Muoni (eds.), Lisola della rinascita. Cinquant'anni di autonomia della Regione Sardegna. Bari: Laterza, 49-54.

A n g i o n i G. 1974. Rapporti di produzione e cultura subalterna. Cagliari: Edes.

A n g i o n i G. 1986. Il sapere della mano. Palermo: Sellerio.

A t z e n i P. 2007. Tra il dire e il fare, Cultura materiale della gente di miniera in Sardegna. Cagliari: Cuec.

A t z e n i P. 20I2a. Knowing how to tell, how to do, how to live. Historical Fragments of Mining Anthropology.

Carbonia: Centro Italiano della Cultura del Carbone.

A tze n i P. 20I2b. Saper dire, saper fare, saper vivere: frammenti storici di antropologia mineraria. Ricerche storiche. Archeologia industriale 42, 3, 435-458.

A tze n i P. 20I5. Il corpo e il cibo, i discorsi e i paesaggi minerari. nei rapporti di produzione e oltre. In F. Bachis and A. M. Pusceddu (eds.), Cose da prendere sul serio. Le antropologie di Giulio Angioni. Nuoro: Il Maestrale, 7I-80.

$\mathrm{B}$ a ch is F. 2017. A Silence Full of Noises: the Aural Environment in a Miner's Life History. ANUAC $6(2), 245-270$.

B all a rd C. and B an ks G. 2003. Resource Wars: The Anthropology of Mining. Annual Review of Anthropology, 32, 287-313.

D'A ng elo L. and P i j pers R. J. 2018. Mining Temporalities: An Overview. The Extractive Industries and Society, 5, 215-222.

D u ra n t i A. 2007. Etnopragmatica. La forza nel parlare. Roma: Carocci.

Feld S. 1991a. Voices of the Rainforest: A Day In The Life Of The Kaluli People. Salem, MA: Rykodisc. CD IoI73.

Feld S. 1991b. Voices of the Rainforest: Politics of Music. Public Culture 4 (I), I3I-40.

Godoy R. 1985. Mining: Anthropological Perspectives. Annual Review of Anthropology I4, 199-2017.

Grims h aw A. and R a vetz A. 20I6. Observational Cinema. Anthropology, Film, and the Exploration of Social Life. Bloomington and Indianapolis: Indiana University Press.

In g o ld T. 20ora. Ecologia della cultura, (a cura di C. Grasseni, F. Ronzon). Roma: Meltemi.

I n g o ld T. 20oIb. From the Trasmission of Representations to the Education of Attention. In H. Whitehouse (ed.), Mind, Evolution and Cultural Trasmission. Oxford: Berg, II3-I53.

In g o ld T. 2007. Against Soundscape. In A. Carlyle (ed.) Autumn Leaves: Sound and the Environment in Artistic Practice. Paris: Double Entendre, IO-I3.

In g o ld T. 20Ira [200o]. The Perception of the Environment. Essays on Livelihood, Dwelling and Skills, Oxon, Routledge.

In g o ld T. 20Irb. Being Alive. Essays on Movement, Knowledge and Description. London. Routledge.

M a c D o u g a 11 D. 1998. Transcultural Cinema. Princeton, Princeton University Press.

M a n c o n i F. (ed.). 1986. Le miniere e i minatori della Sardegna. Cagliari: Edes.

Mille r D. (ed.). 2005. Materiality, Durham, London, Duke University Press.

Ottelli L. 2005. Serbariu. Storia di una miniera. Carbonia: Centro Italiano della Cultura del Carbone.

P a n d e y R. 20I5. Ethnographies of Mining in Late Industrialism. Indian Anthropologist 45 (2), 75-86.

P in k S. 2009. Doing Sensory Ethnography. London: Sage.

Po r telli A. 20I7. Storie orali. Racconto, immaginazione, dialogo, Roma: Donzelli.

R a k ow s k i T. 20I6. Hunters, Gatherers, and Practitioners of Powerlessness. An Ethnography of the Degraded in Postsocialist Poland. New York-Oxford: Berghahn. 
R u j u S. 2008. I mondi minerari della Sardegna (I860-1960) con dieci testimonianze orali, Cagliari: Cuec. S a muels D. W., Meintjes L., Ochoa A. M. and Porcello T. 20I0. Soundscapes: Toward a Sounded Anthropology. Annual Review of Anthropology 39, 329-345.

$\mathrm{S}$ a n g a G. and Viazzo P. 20I6. Introduzione: Minatori nelle Alpi: Prospettive storico-antropologiche. La Ricerca Folklorica 7I, 5-II.

S a pelli G. 2008. Storia economica dell'Italia contemporanea, Milano: Mondadori.

S c h a fe r M. 1994 [1977]. Our Sonic Environment and the Soundscape. The Tuning of the World. Rochester: Destiny Books.

Vi a z z o P. P. 20I6. La cultura della miniera nelle Alpi tra storia e antropologia: Stato delle ricerche e questioni aperte. La ricerca folklorica $7 \mathrm{I}, \mathrm{I} 3-26$

Yo u n g C. 1975. Observational Cinema. In P. Hogkings (ed.), Principles of Visual Anthropology. Berlin, New York: Muyton de Gruyter, 65-80.

\section{Author's contact:}

Felice Tiragallo

Department of Humanities, Languages and Cultural Heritage

University of Cagliari

E-mail:tiragall@unica.it

ORCID: $0000-0002-8$ I $38-55$ I 7

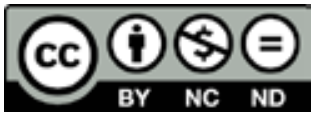


